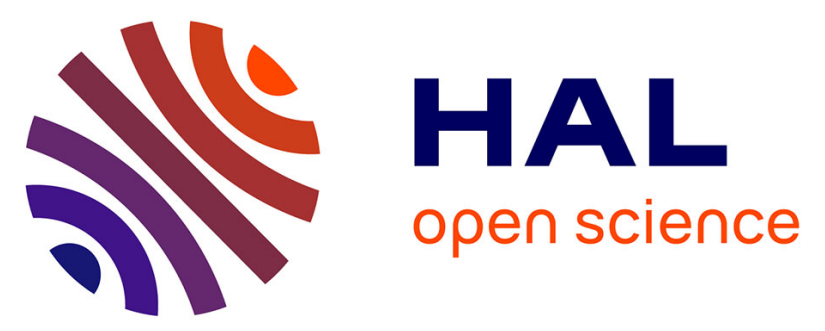

\title{
Hydrogen absorption/desorption reactions of the (TiVNb)85Cr15 multicomponent alloy
}

Bruno Hessel Silva, Claudia Zlotea, Gavin Vaughan, Yannick Champion, Walter José Botta, Guilherme Zepon

\section{- To cite this version:}

Bruno Hessel Silva, Claudia Zlotea, Gavin Vaughan, Yannick Champion, Walter José Botta, et al.. Hydrogen absorption/desorption reactions of the (TiVNb)85Cr15 multicomponent alloy. Journal of Alloys and Compounds, 2022, 901, pp.163620. 10.1016/j.jallcom.2022.163620 . hal-03531809

\author{
HAL Id: hal-03531809 \\ https://hal.science/hal-03531809
}

Submitted on 18 Jan 2022

HAL is a multi-disciplinary open access archive for the deposit and dissemination of scientific research documents, whether they are published or not. The documents may come from teaching and research institutions in France or abroad, or from public or private research centers.
L'archive ouverte pluridisciplinaire $\mathbf{H A L}$, est destinée au dépôt et à la diffusion de documents scientifiques de niveau recherche, publiés ou non, émanant des établissements d'enseignement et de recherche français ou étrangers, des laboratoires publics ou privés. 


\title{
Hydrogen absorption/desorption reactions of the (TiVNb) ${ }_{85} \mathrm{Cr}_{15}$ multicomponent alloy
}

Bruno Hessel Silva ${ }^{\mathrm{a}}$, Claudia Zlotea ${ }^{\mathrm{b} \#}$, Gavin Vaughan ${ }^{\mathrm{c}}$, Yannick Champion ${ }^{\mathrm{d}}$, Walter José

$$
\text { Botta }^{\mathrm{a}, \mathrm{e}} \text {, Guilherme Zepon }{ }^{\mathrm{a}, \mathrm{e}, \#}
$$

a - Federal University of São Carlos, Graduate Program in Materials Science and Engineering (PPGCEM/UFSCar) - Rodovia Washington Luiz, km 235, São Carlos - São Paulo, Brasil CEP:13565-905.

b - Univ Paris Est Créteil, CNRS, ICMPE, UMR 7182, 2 Rue Henri Dunant, 94320, Thiais, France.

c - European Synchrotron Radiation Facility ESRF, BP 220, 38043 Grenoble, France.

d - Univ. Grenoble Alpes, CNRS, G-INP, SIMaP, 38000 Grenoble, France.

e - Federal University of São Carlos, Department of Materials Engineering (DEMa/UFSCar) -

Rodovia Washington Luiz, km 235, São Carlos - São Paulo, Brasil CEP:13565-905.

\# Corresponding authors: zepon@ufscar.br; claudia.zlotea@icmpe.cnrs.fr

\begin{abstract}
Ti-V-Nb-Cr alloys have been reported as potential candidates for hydrogen storage applications. Investigating the processes of absorption and desorption is paramount to understand the hydrogen storage properties of these novel alloys and to develop more efficient hydrogen storage materials. In this work, we investigated the hydrogen absorption/desorption reactions of the (TiVNb) ${ }_{85} \mathrm{Cr}_{15}$ BCC multicomponent alloy by laboratory and synchrotron X-ray diffraction, Pair Distribution Function (PDF) analyses, Transmission Electron Microscopy (TEM) and thermo-desorption analyses (TDS). Hydrogen absorption behavior was studied by pressure-composition-isotherm (PCI) at room temperature, which demonstrated levels of absorption around $2 \mathrm{H} / \mathrm{M}(\mathrm{H} / \mathrm{M}=$ hydrogen-to-metal ratio) with low equilibrium pressure. The results showed a multi-step hydrogenation process: alloy $\leftrightarrow$ BCC solid solution $\leftrightarrow$ BCC intermediate hydride $\leftrightarrow$ FCC dihydride. PDF analyses showed that the partially hydrogenated alloy at different levels of H/M and the fully hydrogenated alloy can be reasonably described by models with phases presenting random atomic distribution in the metal crystallographic sites. Moreover, the partially hydrogenated sample prior to the complete formation of the intermediate hydride showed evidence of two co-existing BCC phases.
\end{abstract}


Keywords: Hydrogen storage; Multicomponent alloy; BCC alloy; Hydrogenation reactions.

\section{Introduction}

Over the last years the world has been struggling with the impact of climate changes caused by global warming, which has been accelerated due to the use of fossil fuels. Renewable energy sources such as solar and wind could be associated with a clean and efficient energy carrier such as hydrogen and provide an environmentally-friendly energy matrix [1-3]. However, several challenges related to hydrogen production and storage methods still need to be overcome to make hydrogen a feasible energy carrier [3,4]. In the context of hydrogen storage technologies, highpressure cylinders are currently the most usual method applied in industry applications. However, the low volumetric efficiency and the high pressures inherently needed are considerable drawbacks of this method [3,4]. Solid-state hydrogen storage using metal hydrides is a relatively safer option taking into account the lower risk for leakage and potential explosions [5,6]. Additionally, metal hydrides offers high volumetric efficiencies at low operation pressures [7-9]. Unfortunately, most of the known conventional metal hydrides present limitations such as low gravimetric storage, sluggish kinetics of absorption/desorption or undesired thermodynamic properties, limiting operation temperature and/or pressure conditions [8,10].

Recently, novel types of alloys known generically as multicomponent alloys expanded the number of systems and compositions available for metal hydride applications. These alloys contain at least three elements with substantial atomic fractions in their composition and often form singlephase solid solutions with atoms randomly organized in their crystal structure [11]. Although these new types of alloys have been extensively analyzed regarding mechanical behavior, the evaluation of functional properties for multicomponent alloys is relatively scarce. In the area of hydrogen storage properties, the number of studies is even smaller. Most of the studies on multicomponent alloys for hydrogen storage focuses on reporting their storage capacity, cycling behavior, pressurecomposition-isotherms and other hydrogenation properties [10-20]. A few correlations between hydrogen storage properties with intrinsic and empiric parameters are reported, such as the effect of alloys' valence electron concentration (VEC) and lattice distortion on the hydrogen storage capacity and other properties [19,21,23,24]. Modelling and computational techniques have been used in the design of multicomponent alloys for hydrogen storage [21,23,25,26]. For example, Zepon et al. [26] developed a thermodynamic model of hydrogen-multicomponent alloy systems 
for the calculation of pressure-composition-temperature diagrams assisted by first principle calculations based on density functional theory (DFT). However, the validation and improvement of such models demand the comprehension of fundamental questions about the structures of possible hydrides and the process of hydrogenation/dehydrogenation in these alloys. This might be a challenging task since numerous differences are reported on the hydrogenation behavior of different systems and compositions reported so far. For instance, single-phase BCC (body centered cubic) alloys, might present FCC (face centered cubic) dihydride formation [23,24], or BCT (body centered tetragonal) dihydride formation [14,27]. Structure parameters such as lattice parameters and lattice strain were initially thought to be able to explain these differences. Sahlberg et al. [27] suggested that the lattice strain in multicomponent alloys could favor hydrogen occupancy in both tetrahedral and octahedral sites generating a BCT dihydride instead of an FCC dihydride. However, recent studies indicated no correlation of these parameters with hydrogen storage capacity $[19,28]$. Also, differences regarding the formation of intermediate hydrides during the hydrogenation process are reported. Some alloys show a two-step hydrogenation process, which indicate the formation of intermediate hydride during hydrogenation [23,24,29,30]. Other alloys are suggested to present a single-step hydrogenation process by directly forming a dihydride $[14,31]$.

Recent works have shown that alloys from the Ti-V-Nb-Cr system might be potential candidates for hydrogen storage. Nygård et al. [24] have reported a reversible storage capacity of $1.96 \mathrm{wt} \% . \mathrm{H}$ at room temperature and moderate $\mathrm{H}_{2}$ pressure for the equiatomic TiVNbCr BCC alloy. The authors claimed that this alloy absorbs hydrogen without the need of any activation procedure and that the obtained reversible capacity is related to the transformation of an FCC dihydride to an intermediate BCC hydride. Strozi et al. [25] evaluated storage properties of (TiVNb) ${ }_{100-x} \mathrm{Cr}_{\mathrm{x}}$ BCC alloys with $\mathrm{Cr}$ content varying from 15 to 35 at.\%. The authors observed that the increasing of the $(\mathrm{Cr} / \mathrm{TiVNb})$ ratio had the effect of increasing the absorption plateau pressure of PCIs at room temperature. The hydrides structures reported in their work seemed to follow the same reactions of absorption proposed by Nygard et al. [24]. However, during absorption, the alloys with higher $\mathrm{Cr}$ content apparently formed intermediate hydrides with lower $\mathrm{H} / \mathrm{M}$ capacity. In a previous work [23], we investigated hydrogen storage properties of the (TiVNb) ${ }_{85} \mathrm{Cr}_{15}$ alloy and we also suggested the formation of an intermediate BCC hydride. X-ray diffraction (XRD) analyses of samples subjected to 20 cycles of absorption have shown a small 
remaining amount of a possible BCC intermediate hydride suggesting incomplete transformation of this phase to the FCC dihydride. In summary, these works called the attention for the formation of intermediate hydrides in alloys of the Ti-V-Nb-Cr system and discussed the effects of these phases on the reversible hydrogen storage capacity. However, the hydrogenation reactions of these alloys are not completely clear yet. Thus, the present work is focused on a detailed study about the hydrogen absorption/desorption reactions of the (TiVNb) ${ }_{85} \mathrm{Cr}_{15}$ multicomponent alloy.

\section{Materials and Methods}

\subsection{Synthesis of the alloy}

The (TiVNb) ${ }_{85} \mathrm{Cr}_{15}$ composition was selected based on the hydrogen storage properties of this alloy reported in our previous study [23]. Preliminary results showed the formation of stable hydrides with low hydrogen equilibrium pressures at room temperature, which is appropriate for the investigation of hydride structures. The synthesis of the ( $\mathrm{TiVNb}_{85} \mathrm{Cr}_{15}$ alloy was performed in an arc-electric melting furnace under argon atmosphere. Initially, only $\mathrm{Ti}$ and $\mathrm{Nb}$ pieces were melted to form a binary alloy and subsequently, $\mathrm{V}$ and $\mathrm{Cr}$ pieces were added and melted to obtain the desired alloy (this procedure was adopted to avoid incomplete fusion of Nb pieces). The alloy was remelted five times, turning the piece upside down between each remelt step in order to improve chemical homogenization. The $\mathrm{Ti}, \mathrm{V}, \mathrm{Nb}$ and $\mathrm{Cr}$ pieces used to synthesize the alloy have purity level higher than $99.7 \%$. Ti getter pieces were melted prior to the alloy's synthesis to minimize oxygen content in the melting chamber. Moreover, the alloy was stored in a Mbraun glovebox under argon atmosphere with levels of $\mathrm{O}_{2}$ and $\mathrm{H}_{2} \mathrm{O}$ lower than 0.5 ppm.

\subsection{Hydrogen absorption and desorption experiments}

To perform hydrogen sorption experiments, small pieces of the alloy were cut using a manual shear cutter and loaded in a Sieverts-type apparatus. Absorption experiments subjecting samples to 25 bar of hydrogen were performed at room temperature without prior activation treatment. However, no significant hydrogen absorption was observed at this condition. Therefore, activation treatments at $390{ }^{\circ} \mathrm{C}$ for 12 hours under dynamic vacuum were performed to facilitate hydrogen absorption by the samples. PCI measurement at room temperature was performed to evaluate the maximum capacity of the alloy and to determine intermediate absorption conditions to study the absorption reactions. Some samples were partially hydrogenated with different hydrogen concentration. The appropriate hydrogen pressure dose at room temperature was applied 
to reach the desired hydrogen concentrations. Before each partial hydrogenation, one complete cycle of absorption at room temperature and 25 bar and desorption at dynamic vacuum (10 ${ }^{-3}$ bar) at $390{ }^{\circ} \mathrm{C}$ was carried out to ensure the full activation of the alloy. This procedure also ensured the complete pulverization of the partially hydrogenated alloys, which was paramount for subsequent X-Ray diffraction (XRD) analyses. Thermal Desorption Spectroscopy (TDS) experiments were performed to investigate the desorption reactions of the hydrogenated samples. The experiments were carried out in a homemade apparatus equipped with a quadrupole mass spectrometer, which recorded partial pressure of $\mathrm{H}_{2}$. This equipment was attached to a secondary vacuum pump, which provided vacuum pressures of $10^{-6}$ mbar. For the desorption tests, hydrogenated samples of 10-15 mg were inserted in aluminum crucibles and then heated at $5^{\circ} \mathrm{C} / \mathrm{min}$ up to $450{ }^{\circ} \mathrm{C}$.

\subsection{Structural analyses}

XRD analyses were performed in a D8 Advance Bruker diffractometer with $\mathrm{Cu}-\mathrm{K} \alpha$ radiation $\left(\lambda_{\mathrm{K} \alpha 1}=1.5406 \AA, \lambda_{\mathrm{K} \alpha 2}=1.5444 \AA\right)$. Synchrotron radiation powder X-ray diffraction (SRXRD) measurements were carried out at ID15A beamline at ESRF, Grenoble (France) [32]. Incident flux was normalized using a diode placed in front of the sample. Diffraction patterns were collected in transmission geometry by using a Pilatus3 X CdTe 2M hybrid photon counting detector. A number of diffraction patterns were collected at slightly different detector positions for each sample, in order to minimize inhomogeneity effects and cover dead zones. The detector was off-centered with respect to the $99 \mathrm{keV}$ incident beam and positioned close to the sample to access q values up to $\sim 30 \AA^{-1}$. The images were corrected for detector geometry, response, distortion and transparency and for the background contributions and X-ray polarization. Data were azimutally integrated using a modified version [33] of the PyFAI library [34] to give one dimensional scattering patterns. The $G(r)$ were calculated from these patterns using routines from the DiffpyCMI library [35] with local modifications for outlier rejection and treatment of background. The selected X-ray wavelength for these analyses was $0.1252365 \AA$ (99 keV). Rietveld refinement analyses were performed using the General Structure Analysis System II (GSASII) software [36]. Pair-Distribution-Function (PDF) analyses were performed with the help of PDFgui program [37]. Transmission electron microscopy (TEM) analyses were performed using a field emission gun FEI Tecnai G2F20 microscope coupled with an Energy Dispersive X-ray Spectrometer (EDS) detector. A TEM sample from the partially hydrogenated alloy was prepared by crushing the powder 
resulted from hydrogenation experiment using a mortar and pestle. The crushed powders were immersed in isopropyl alcohol and left for 30 minutes in an ultrasonic bath. The fine powders were collected with a pipette and deposited onto a carbon coated cooper grid.

\section{Results and discussion}

The absorption/desorption reactions of the (TiVNb) ${ }_{85} \mathrm{Cr}_{15}$ alloy are detailed in Figure 1. Figure 1 (a) shows the PCI of the ( $\mathrm{TiVNb})_{85} \mathrm{Cr}_{15}$ alloy at room temperature. The alloy presented a hydrogen uptake of up to $\sim 2 \mathrm{H} / \mathrm{M}$ at low equilibrium pressures, as reported for other multicomponent alloys $[19,23,24,30]$. Four samples of this alloy were partially hydrogenated with different amounts of hydrogen, as indicated in Figure 1 (a) by black arrows and numbers from 1 to 5. Figure 1 (b) presents the XRD patterns of the as-cast sample (1) and of the four partially hydrogenated samples (2-5). The Rietveld refinements of these patterns are shown in Figure S1 of the supplementary file. The lattice parameters and phase concentrations determined by Rietveld refinement are listed in Table 1. The XRD pattern of the as cast sample (1) shows that the alloy solidified as a single-phase BCC structure $(\operatorname{Im} \overline{3} m)$, with lattice parameter of $\mathrm{a}_{\mathrm{BCC}}=3.164$ (1) $\AA$. Subsequently, the XRD pattern of sample with $\mathrm{H} / \mathrm{M}=0.5$ (2) presented broader diffraction peaks, suggesting two co-existing BCC phases with different lattice parameters, both greater than the lattice parameter of the as cast sample. We hypothesize that the close lattice parameters of both BCC phases results in an overlapping of the Bragg peaks. This consideration will be further analyzed in this manuscript. Different lattice parameters indicate different $\mathrm{H}$ content in the BCC phases. Such co-existence of two phases with same structure and different $\mathrm{H}$ concentration suggests a miscibility gap, like the one observed for Ti-Cr-V BCC alloys reported by Tamura et al. [38,39]. Therefore, the BCC with lower hydrogen concentration is possibly a random $\mathrm{H}$ solid solution (which we will refer at this work as BCC solid solution phase) while the one with higher $\mathrm{H}$ content is an intermediate hydride. Increasing the $\mathrm{H}$ concentration to $0.83 \mathrm{H} / \mathrm{M}$, sample (3), a single BCC phase $(\operatorname{Im} \overline{3} m)$ was detected with larger lattice parameter than the ones of the BCC solid solution phase and the intermediate BCC hydride from sample (2). This indicates an increase in the hydrogen concentration of the intermediate hydride. A mixture of the intermediate BCC hydride and a FCC dihydride phase $(F m \overline{3} m)$ is observed for sample (4) with $1.6 \mathrm{H} / \mathrm{M}$. Interestingly, the lattice parameter of the BCC phase did not change from (3) to (4), suggesting that the maximum hydrogen concentration of the intermediate hydride is reached at a capacity of $0.83 \mathrm{H} / \mathrm{M}$. Strozi et 
al. [25] also reported the formation of an intermediate BCC hydride for the (TiVNb) ${ }_{65} \mathrm{Cr}_{35}$ alloy with maximum amount of hydrogen stored around $0.8 \mathrm{H} / \mathrm{M}$ according to PCI measurement. However, in their case the PCI measurement seems to present a wider plateau pressure in absorption than in desorption. In our previous study [23], we measured high temperature PCIs for the ( $\mathrm{TiVNb}{ }_{85} \mathrm{Cr}_{15}$ alloy and the curves seemed to present two plateau pressures in absorption and desorption, although the first plateau pressure could not be accurately determined. It is not clear the reasons for these differences, and this should be investigated in future works since it affects the reversible storage capacity of the alloys. Lastly, after complete absorption (5), only the dihydride phase is detected with a slightly larger lattice parameter than in (4), which is explained by the higher $\mathrm{H}$ content in the hydride for this condition. The formation of FCC dihydrides after complete hydrogenation is frequently reported in BCC multicomponent alloys [19,23,24,29,30].

The desorption processes of the (TiVNb) ${ }_{85} \mathrm{Cr}_{15}$ alloy were investigated by performing thermal desorption tests of samples (2), (3), (4) and (5). Figure 1 (c) shows the thermal desorption profiles associated to each sample. The samples with 0.5 and $0.83 \mathrm{H} / \mathrm{M}$, samples (2) and (3), presented a single desorption peak with maximum at 340 and $320^{\circ} \mathrm{C}$, respectively. According to the XRD and PCI results, the desorption from theses samples can be related to two main events: 1) the desorption of the intermediate hydride 2) the desorption of the solid solution phase. The desorption profiles look similar though the onset and maximum temperatures are slightly different from one sample to another. This might be explained by the difference in the phase present in each sample. Sample (2) present a fraction of solid solution and a fraction of intermediate hydride (with $\mathrm{H}$ concentration estimated of 0.31 and $0.67 \mathrm{H} / \mathrm{M}$, as will be discussed later), whereas sample (3) is composed solely of the intermediate hydride with $0.83 \mathrm{H} / \mathrm{M}$. However, it is worth noting that the desorption peaks from the intermediate hydride and solid solution phase cannot be resolved for sample (2) and (3). Sample (4) with $1.6 \mathrm{H} / \mathrm{M}$ displayed in addition to a high temperature peak (associated with the desorption of the intermediate and solid solution phase) a noisy desorption peak with lower onset temperature $\left(160^{\circ} \mathrm{C}\right)$. According to the XRD and PCI data, these steps are probably related to the desorption of the FCC dihydride phase. Lastly, the completely hydrogenated sample (5) shows an even larger desorption profile at lower temperature, starting at $50{ }^{\circ} \mathrm{C}$, with two main very large peaks with maximum located at around 150 and $330{ }^{\circ} \mathrm{C}$, respectively. These events probably correspond to the desorption of the dihydride (irregular profile at low temperature), and intermediate hydride / solid solution phases (smooth profile at high 
temperature). Yet, it is not fully understood why the desorption of the dihydride phase (in the low temperature range) shifts to lower temperature as compared to sample (4). The preferential occupation of $\mathrm{H}$ in interstitial sites with specific atomic neighbors (low VEC of neighboring atoms) as well as the jumping of $\mathrm{H}$ atom from one interstitial sites to another have been proposed recently in the literature [28,40], and could have some relation with the irregular desorption profile.

The main features of the TDS data can be well understood by the following desorption reactions: $\mathrm{FCC}$ dihydride $\rightarrow \mathrm{BCC}$ intermediate hydride $\rightarrow \mathrm{BCC}$ solid solution $\rightarrow$ hydrogen free BCC alloy. It is worth mentioning that high temperature $\left(100{ }^{\circ} \mathrm{C}, 150{ }^{\circ} \mathrm{C}\right.$, and $\left.200{ }^{\circ} \mathrm{C}\right)$ PCI measurements in absorption and desorption were reported for the (TiVNb) ${ }_{85} \mathrm{Cr}_{15}$ alloy in [23]. The high temperature PCI measurements suggest the presence of two plateaus, which is consistent to our findings given that the first plateau might be associated to the formation of the intermediate hydride and the second plateau associated to the formation of the dihydride.

Table 1: Lattice parameters and phase concentrations (\%) of the initial, partially and fully hydrogenated samples together with the results from the cycled sample determined by XRD, SRXRD and PDF analyses. BCC1 and BCC2 refers to the solid solution phase and the intermediate hydride respectively.

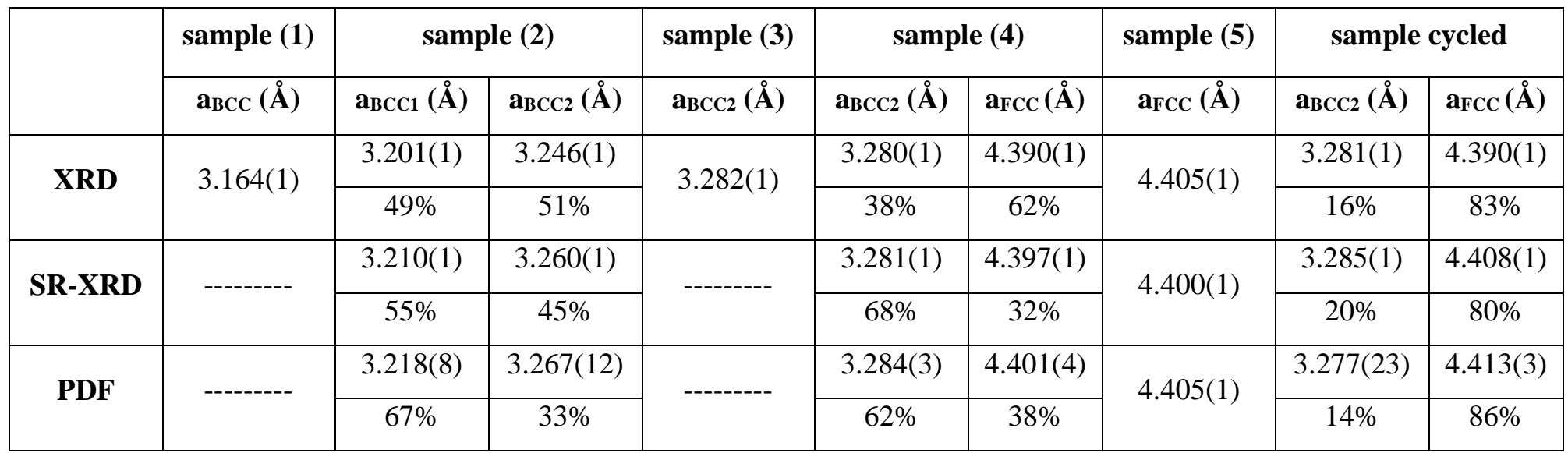


(a)

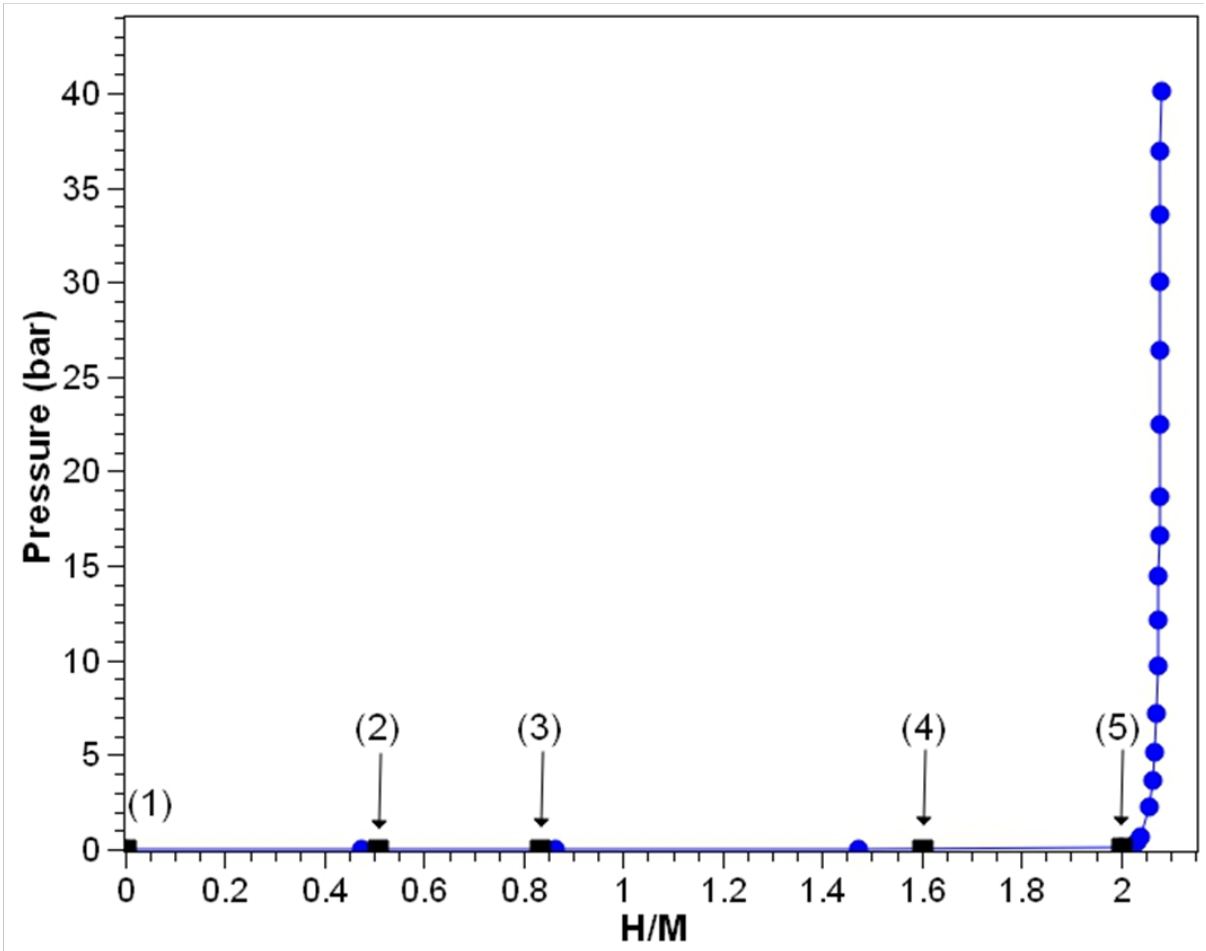

(b)

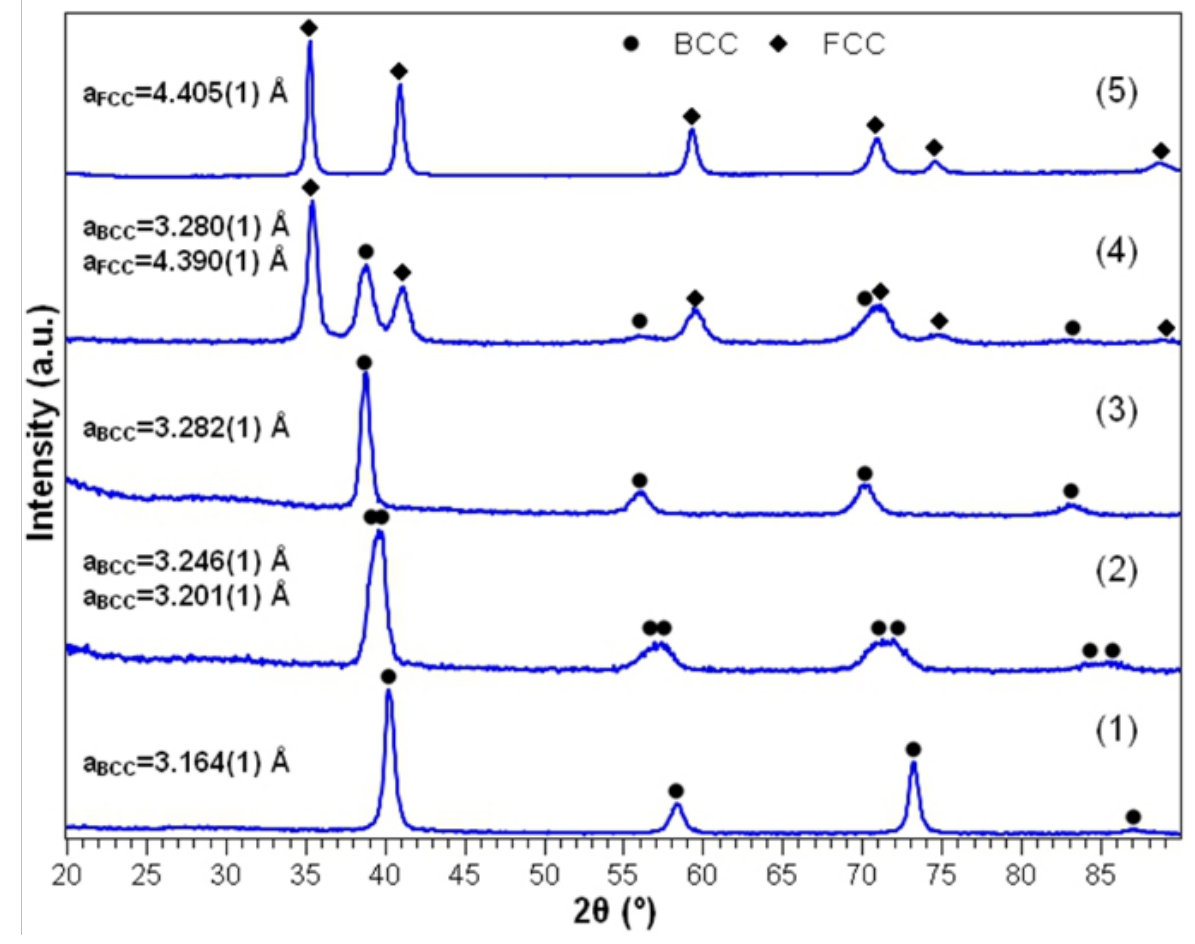




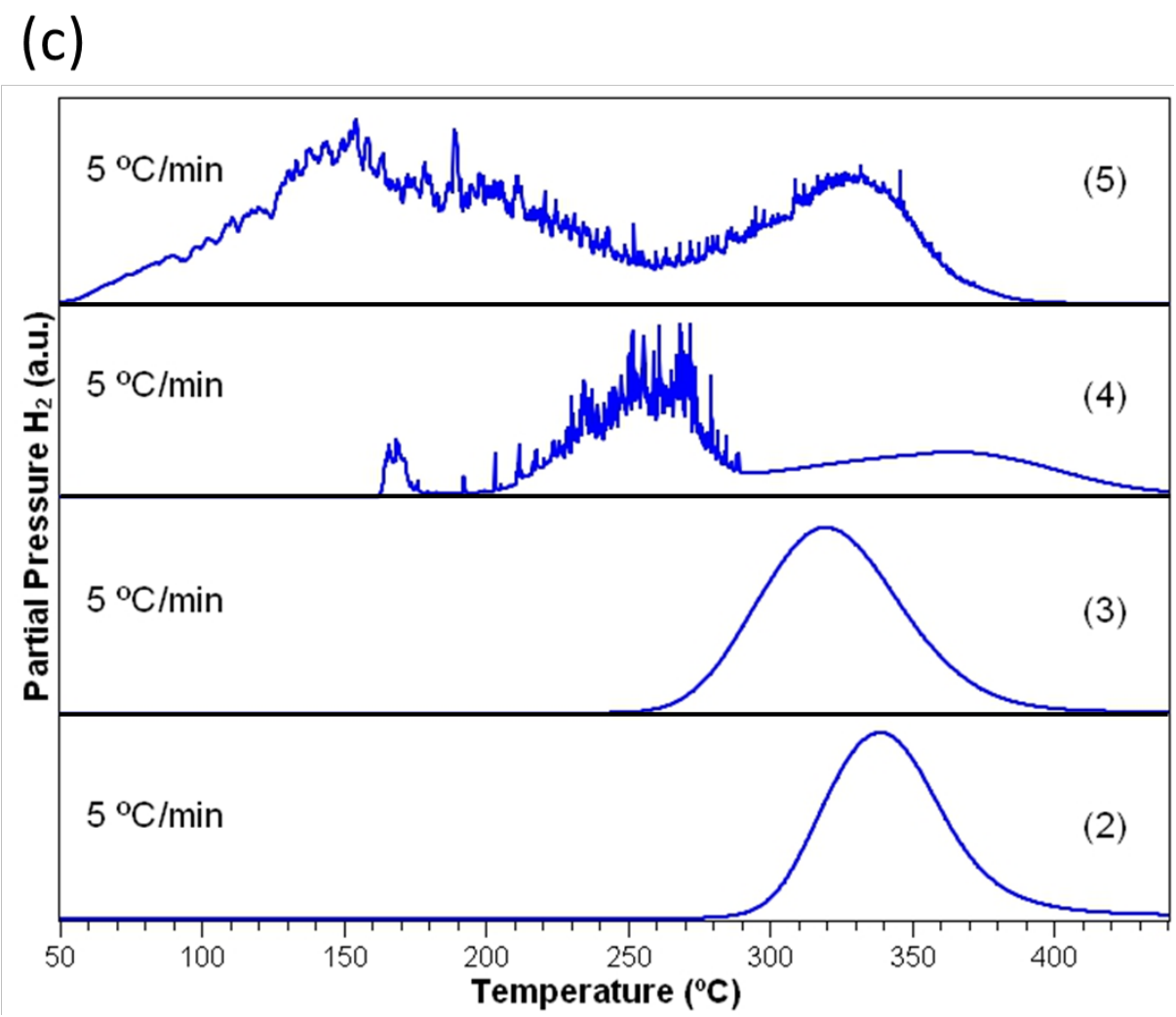

Figure 1: Hydrogenation/dehydrogenation reactions of the ( $\mathrm{TiVNb}{ }_{85} \mathrm{Cr}_{15}$ alloy with (a) PressureComposition-Isotherm at room temperature indicating the 5 conditions analyzed (b) XRD patterns showing phase evolution during hydrogenation (c) Thermo-desorption profiles of hydrides samples from each step of the hydrogenation process.

Structural characterization via SR-XRD analyses were performed in samples (2), (4) and (5). Figures 2 (a)-(c) show the Rietveld refinements analyses obtained by SR-XRD of samples (2), (4), and (5), respectively. The obtained phase concentrations and lattice parameters are listed in Table 1 . The main features observed in the laboratory XRD analyses are confirmed by the SRXRD results: broad diffraction peaks in sample (2) indicating co-existence of two BCC phases; mixture of BCC and FCC phases in sample (4); and the complete hydrogenated sample (5) presenting only the FCC phase. The fitting of the SR-XRD pattern of sample (2) with two coexisting BCC phases showed a good agreement with experimental data supporting once more the hypothesis of a miscibility gap for the formation of the intermediate hydride. Figure 3 shows in detail the splitting and deconvolution of the (222) diffraction reflections of the two co-existing BCC phases supporting our initial hypothesis. The values of lattice parameters and phase 
concentrations determined for sample (2) using SR-XRD are reasonably similar to the ones found by laboratory XRD (see Table 1). Some minor deviations are noticed but we consider that these deviations might be related to Rietveld refinement inaccuracies of the laboratory XRD analyses/data, since the pattern of SR-XRD presents improved signal/background ratio allowing a much more accurate refinement. Considering the volume expansion of the unit cell of the BCC phase in sample (3) as $3.678 \AA^{3}$ (which absorbed $0.83 \mathrm{H} / \mathrm{M}$ ) we estimated the volume increase per hydrogen atom as $2.216 \AA^{3}$. Therefore, given the lattice parameters of both BCC phases in sample (2), we estimated the hydrogen concentration of the two BCC phases as being around 0.31 and $0.67 \mathrm{H} / \mathrm{M}$. These values are consistent with the phase fractions found by Rietveld refinement, since multiplying the phase fractions by the estimated concentrations the resulting absorption is 0.47 $\mathrm{H} / \mathrm{M}$ which is very close to the hydrogen concentration of sample (2), i.e. $\mathrm{H} / \mathrm{M}=0.5$. The SR-XRD results of sample (4) shows a substantial reduction in the FCC phase concentration in comparison to the results observed on laboratory XRD (see Table 1). It is important to mention that the SRXRD experiments were performed 250 days after the laboratory XRD experiments. Nevertheless, this brings the possibility of sample (4) presenting spontaneous desorption after long periods of time resulting in the decomposition of the FCC dihydride. To confirm this hypothesis, another laboratory XRD test was performed in sample (4) after 390 days from the initial XRD experiments. Figure S2 (a) of the supplementary file shows the evolution of phase concentrations in sample (4) over time, confirming a continuous reduction of the FCC phase. Nygard et al. [24] have reported a similar spontaneous desorption behavior in a hydride sample of the TiVNbCr alloy. According to the authors, the sample of $\mathrm{TiVNbCrH}_{\mathrm{x}}$ was left at RT in a glovebox at 1 bar of Argon and presented complete decomposition of the FCC dihydride after 100 days. However, in our work, the complete hydrogenated sample (5) have not showed any sign of spontaneous decomposition of the FCC dihydride according to XRD and SR-XRD (see Figure 1 (a) and Figure 2 (c)). Another laboratory XRD test was performed in sample (5) after 390 days of the initial XRD analyses and the sample still presented only the FCC dihydride indicating no sign of decomposition (see Figure S2 (b) of the supplementary file). The reasons for the different behavior regarding the dihydride decomposition in samples (4) and (5) are not yet clear and should be further investigated in future works. 
(a)

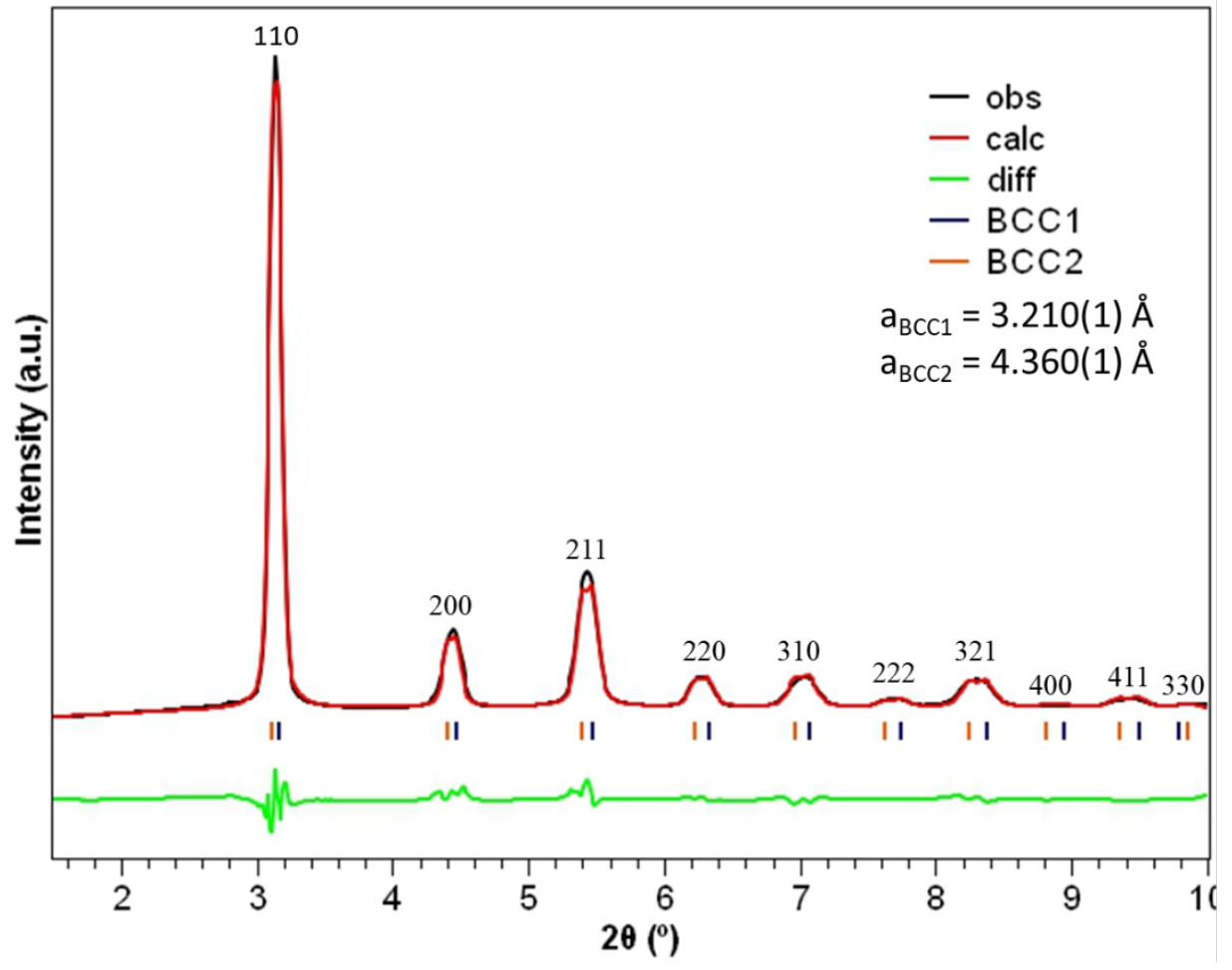

(b)

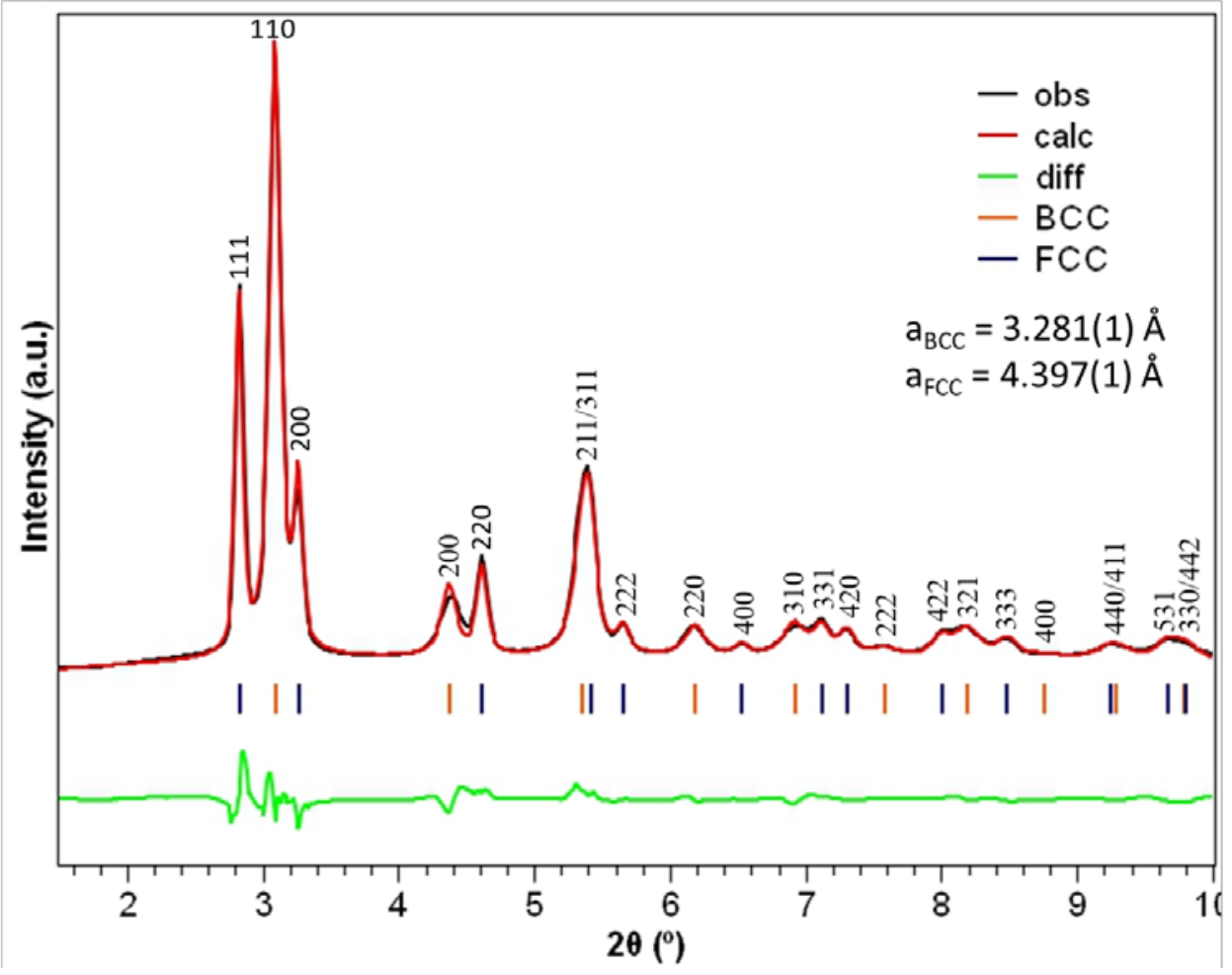




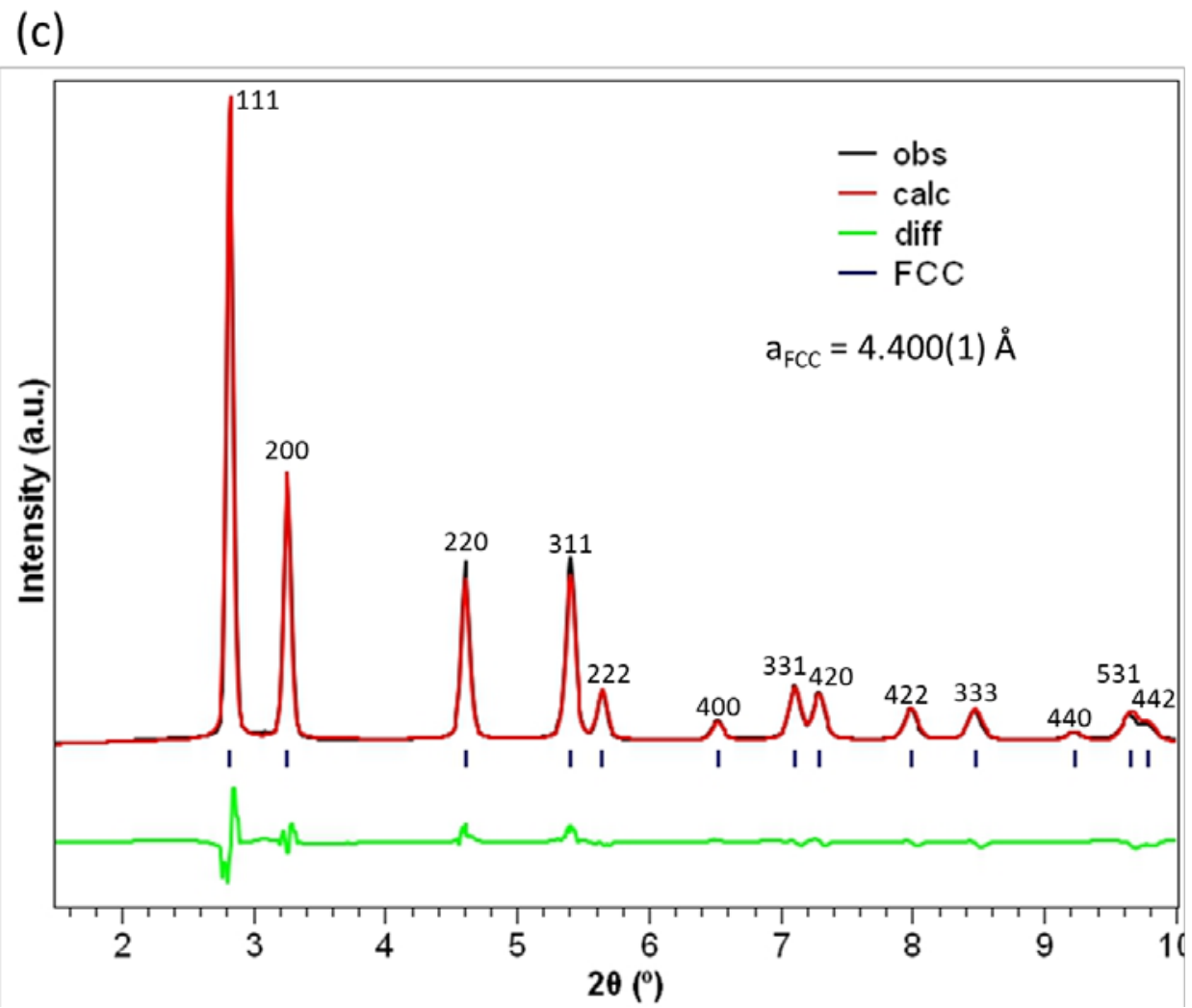

Figure 2: SR-XRD Rietveld refinement analyses of the diffraction patterns from samples (a) (2), (b) (4) and (c) (5). 


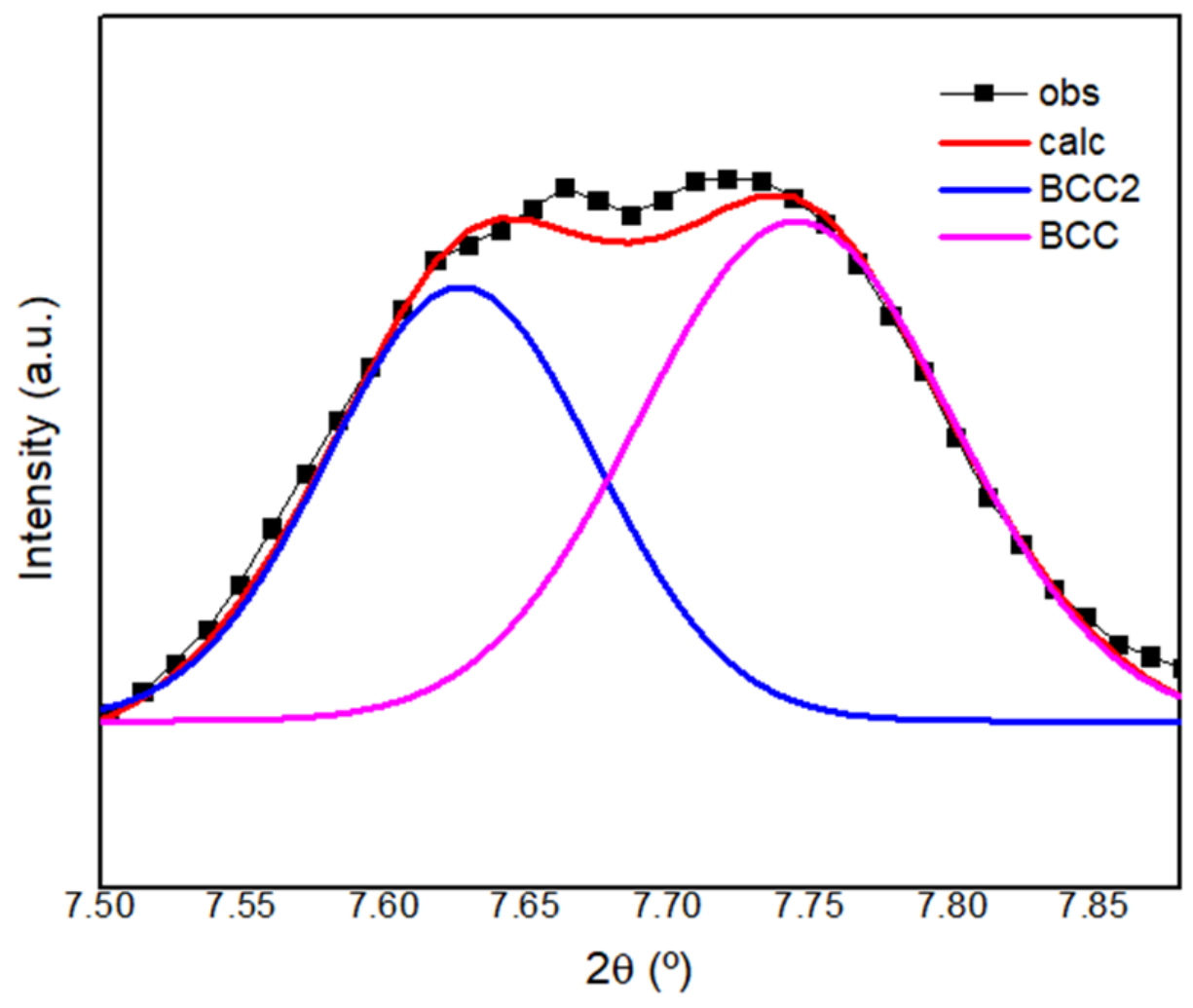

Figure 3: Deconvolution of the (222) diffraction reflections form the two BCC phases of sample (2) measured by SR-XRD.

Further structural characterization of samples (2), (4) and (5) was performed by PDF analyses. Figure 4 (a)-(c) show the PDF analyses from samples (2), (4), and (5), respectively. The fitting of PDF data from sample (2) with two co-existing BCC phases shows good agreement with the experimental data as exhibited in Figure 4 (a). In this case, the PDF data is fitted using two undistorted BCC models with random atomic distribution in the metal crystallographic sites of the BCC structure, i.e., without any local ordering. The good fit between the experimental data and the PDF model suggests that the medium structure in the high-R region and the local structure in the low-R range can be well described by a combination of two random BCC structures with different lattice parameters. Therefore, this average model can explain all observed features in the PDF data without any evidence of short-range ordering introduced by $\mathrm{H}$ absorption. The PDF analyses from samples (4) and (5) - as can be seen in Figure 4 (b) and (c) - also show good agreement between the experimental data and the fittings using undistorted models with random atomic distribution in the metal crystallographic sites for the FCC and BCC structures for sample 
(4) and FCC structure for sample (5). Previous works also demonstrated by X-ray and neutrons scattering PDF analysis the absence of short range order (SRO) of the metal atoms for the TiVNb, TiVZrNb and TiVZrNbHf alloys [28,41]. It also has been reported that the lattice distortion is relieved when hydrides with $\mathrm{CaF}_{2}$-type structures are formed from these BCC refractory HEAs, which is consistent to our findings [41]. The lattice parameters and phase concentrations determined by PDF analyses are listed in Table 1. Values of atomic displacement parameters are available on Table S1 of the supplementary file. Although a slightly higher amount of the solid solution BCC phase was found in sample (2) by PDF in comparison to SR-XRD results, the agreement of the values from lattice parameters and the phase concentrations obtained by PDF and SR-XRD analyses are quite reasonable.

Additional SR-XRD and PDF analyses were performed in a hydride sample of (TiVNb) ${ }_{85} \mathrm{Cr}_{15}$ alloy submitted to 20 cycles of desorption at $390{ }^{\circ} \mathrm{C}$ and 20 cycles of absorption at room temperature. For more details of this sample, the reader is referred to the previous work [23]. The aim of these additional analyses was to investigate the cycling effect on the average and local crystalline structure of this sample. Figures 5 (a), (b), (c) show the XRD, SR-XRD and PDF results, respectively, obtained for this sample. The lattice parameters and phase concentrations determined by these analyses are listed in Table 1 . Values of atomic displacement parameters are available in Table S1 of the supplementary file. The three analyses show a mixture of a major FCC dihydride phase with a small amount of BCC intermediate hydride. We suggest that this small amount of intermediate hydride is a result of incomplete hydrogenation, which led to a slight reduction of the maximum hydrogen uptake after cycling [23]. The PDF analyses shows that the fitting using two undistorted BCC and FCC structure with random atomic distribution in the respective metal crystallographic sites is able to reasonably describe the experimental data. Therefore, no evidence of short-range ordering is observed even after cycling. 
(a)

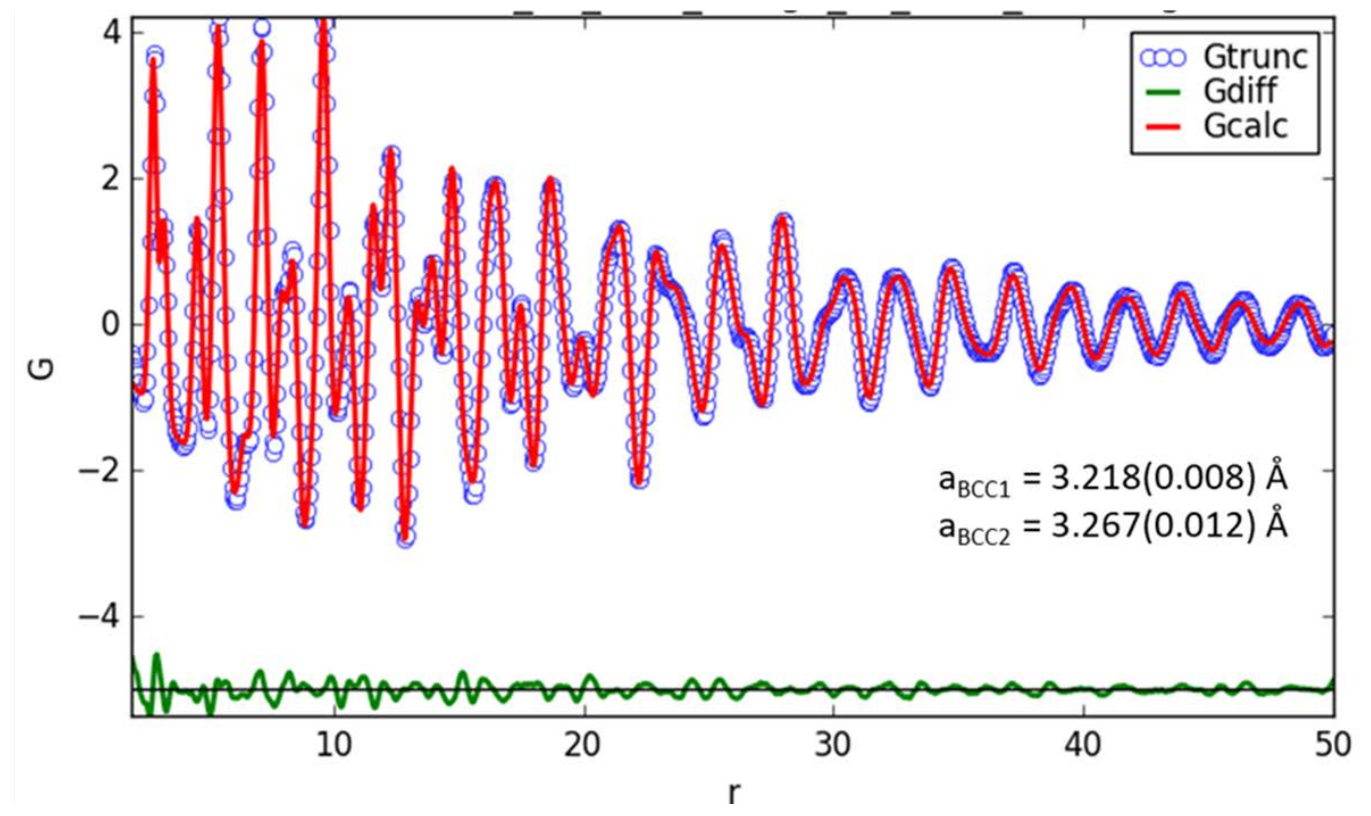

(b)

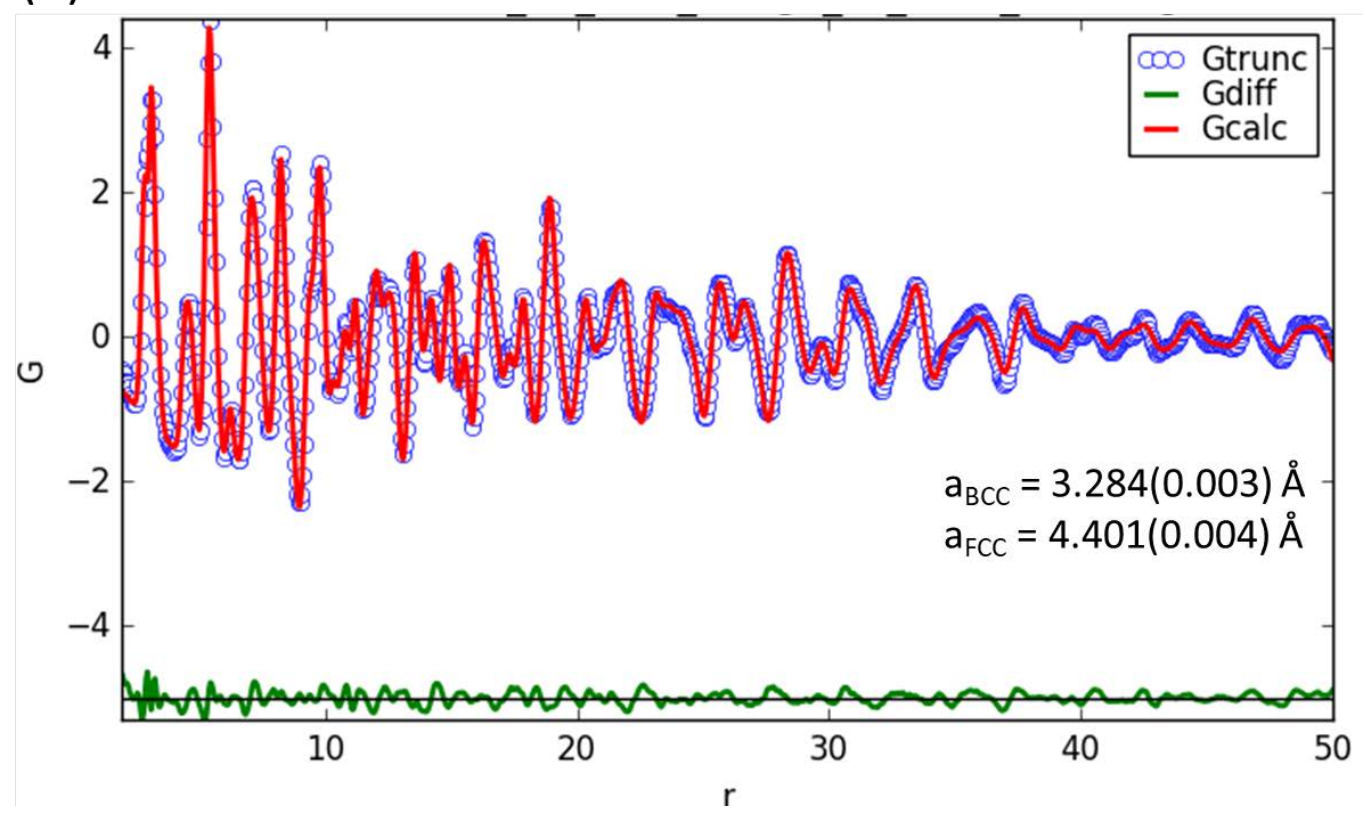


(c)

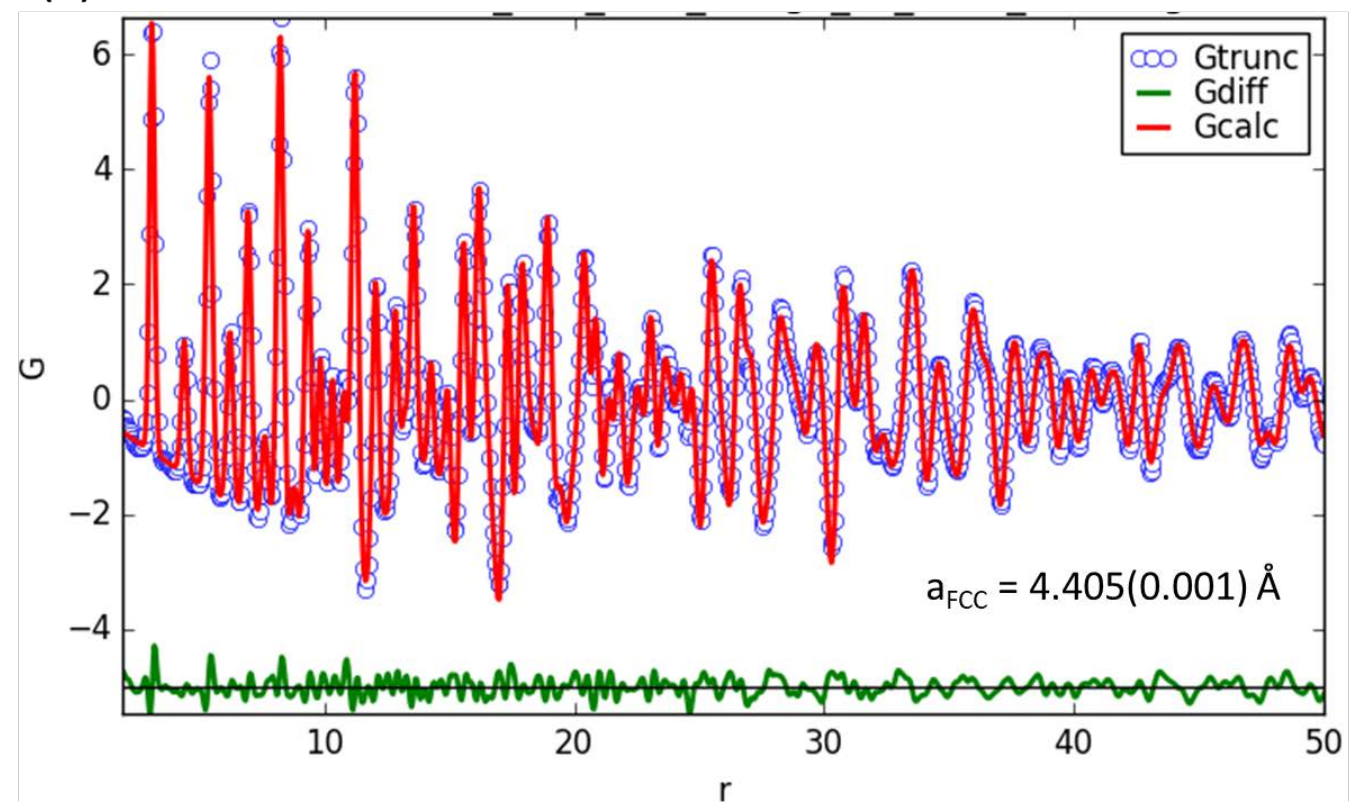

Figure 4: Pair-Distribution-Function (PDF) analyses from samples (a) (2), (b) (4) and (c) (5). BCC1 and BCC2 refers to the solid solution and the intermediate hydride phases, respectively.

(a)

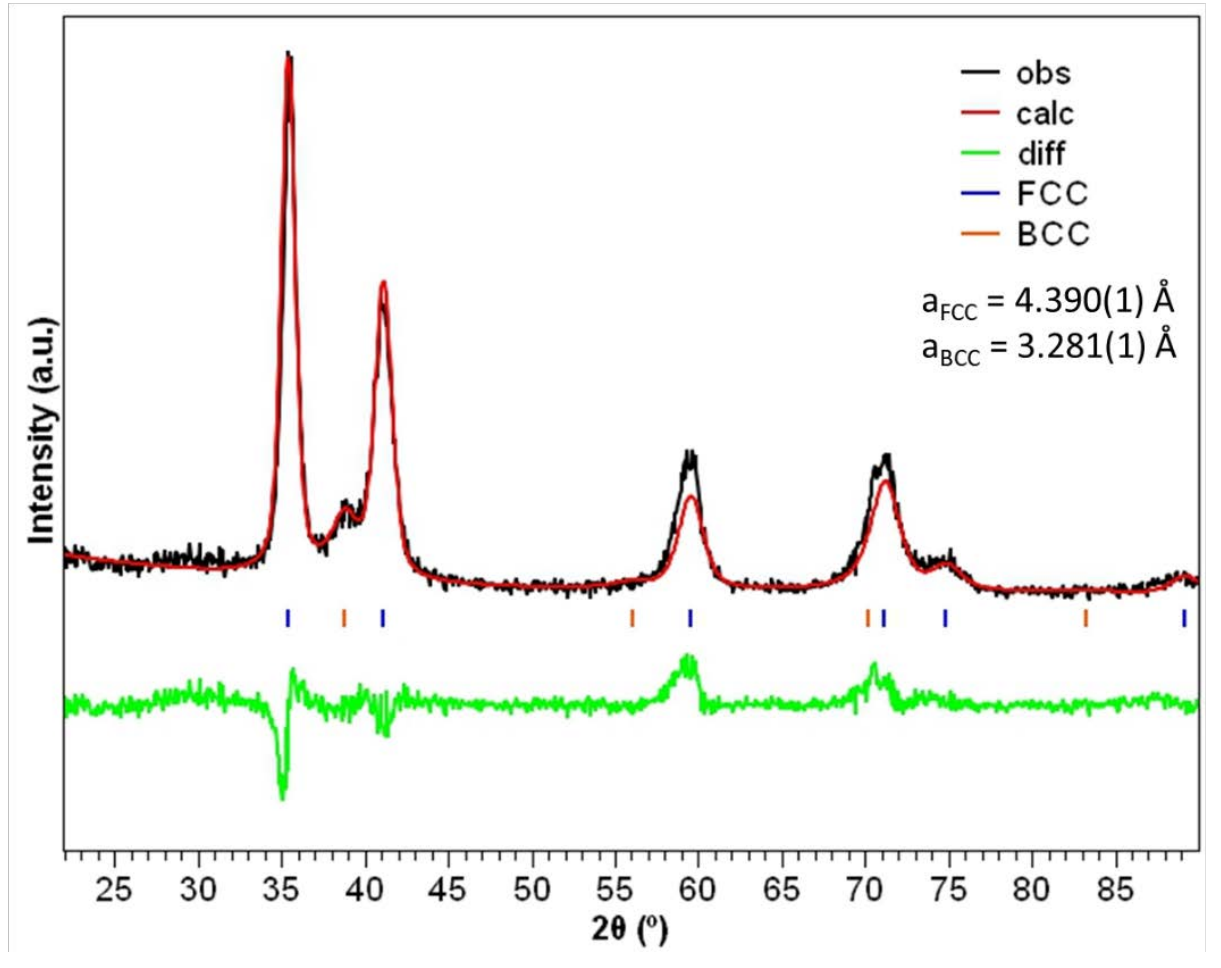


(b)

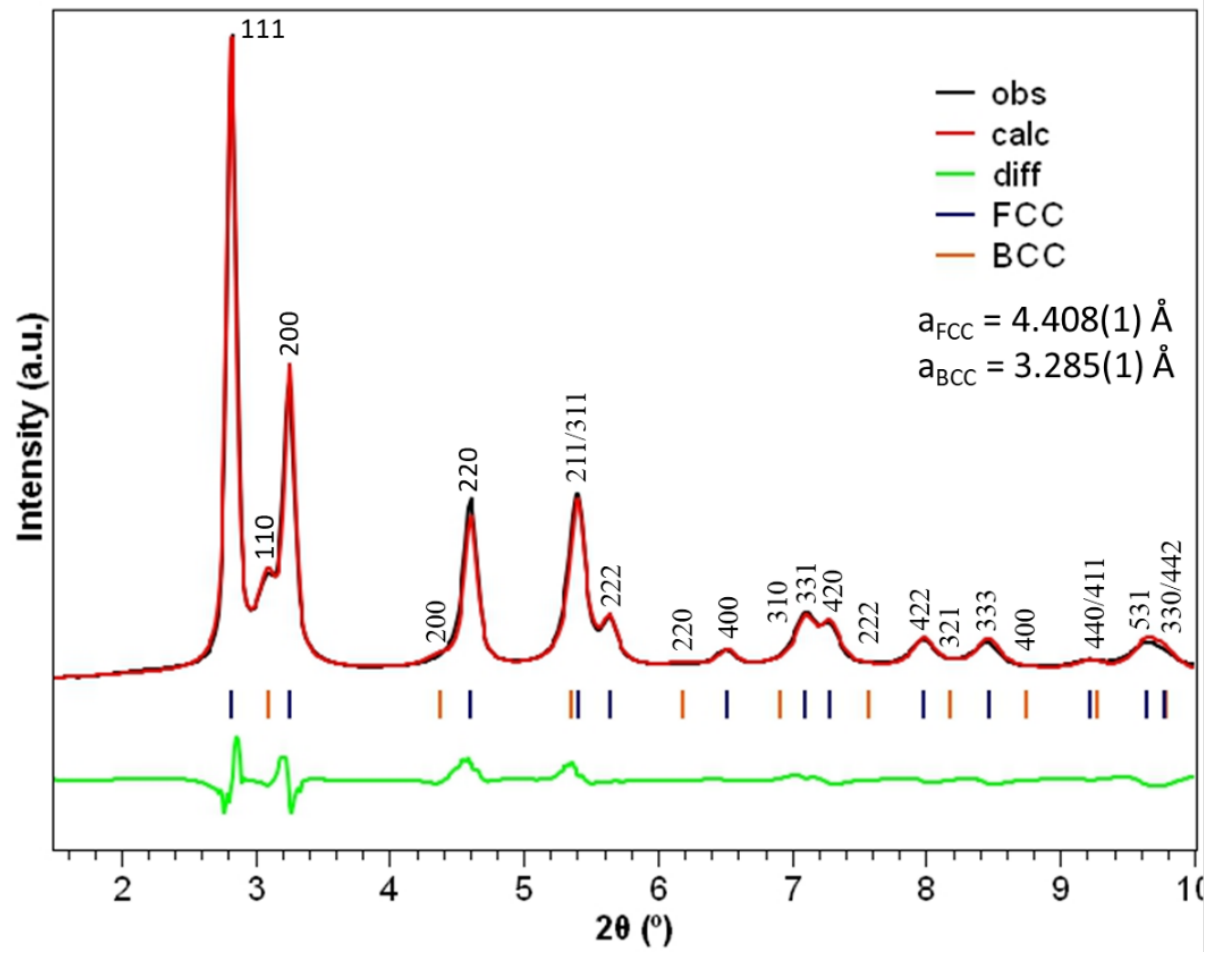

(c)

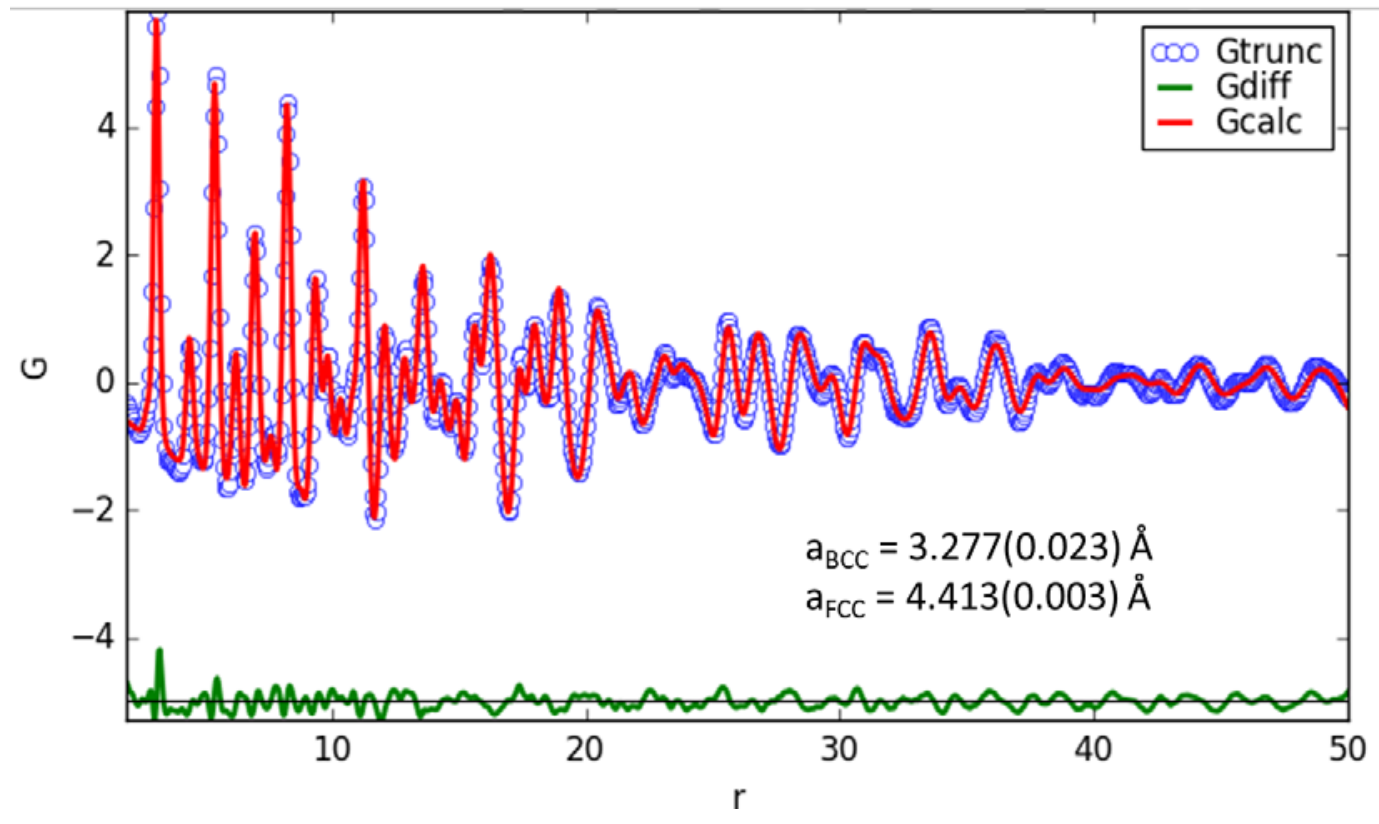

Figure 5: (a) XRD, (b) SR-XRD and (c) PDF analyses of (TiVNb) ${ }_{85} \mathrm{Cr}_{15} \mathrm{H}_{\mathrm{x}}$ hydride after 20 cycles of desorption/absorption. 
TEM images of a single powder particle from sample (2) with $\mathrm{H} / \mathrm{M}=0.5$ are shown in Figure 6. The chemical composition of this single particle measured by TEM-EDS was very close to the nominal composition as can be seen in Table 3. Figure 6 (e) displays the EDS map showing that the sample is chemically homogeneous. The bright and dark-field images - Figure 6 (a) and (c) - show that the particle has a nanocrystalline structure, which is confirmed by the selected area electron diffraction pattern (SAEDP) in Figure 6 (b). The SAEDP shows a ring diffraction pattern corresponding to a BCC structure. Because of the inelastic scattering that occurs in TEM electron diffraction, the resolution of the diffraction pattern is much lower than that of laboratory XRD or SR-XRD and, therefore, we did not expect to resolve the diffraction rings of the two BCC phases. However, the contrast modulation observed in the dark-field images acquired using the 110-ring reflection - Figure 6 (c) and (d) - confirms the presence of structure features at nanoscale that might be related to the co-existence of two different phases. In Figure 6 (d) the interference fringes separated by few nanometers delimitates different structural zones, which might be related to differences between the BCC phases, such as the different lattice parameters, for example.

\section{(a)}

(b)

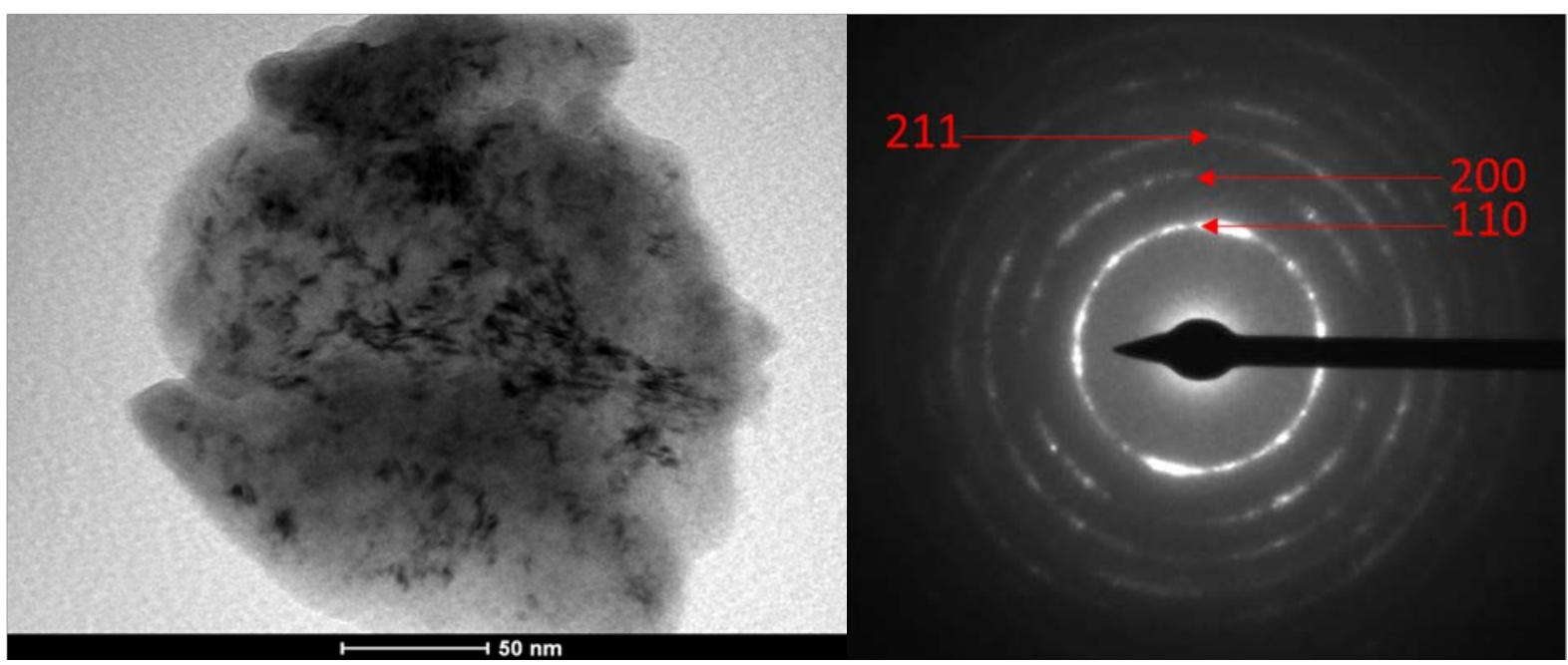


(c)

(d)

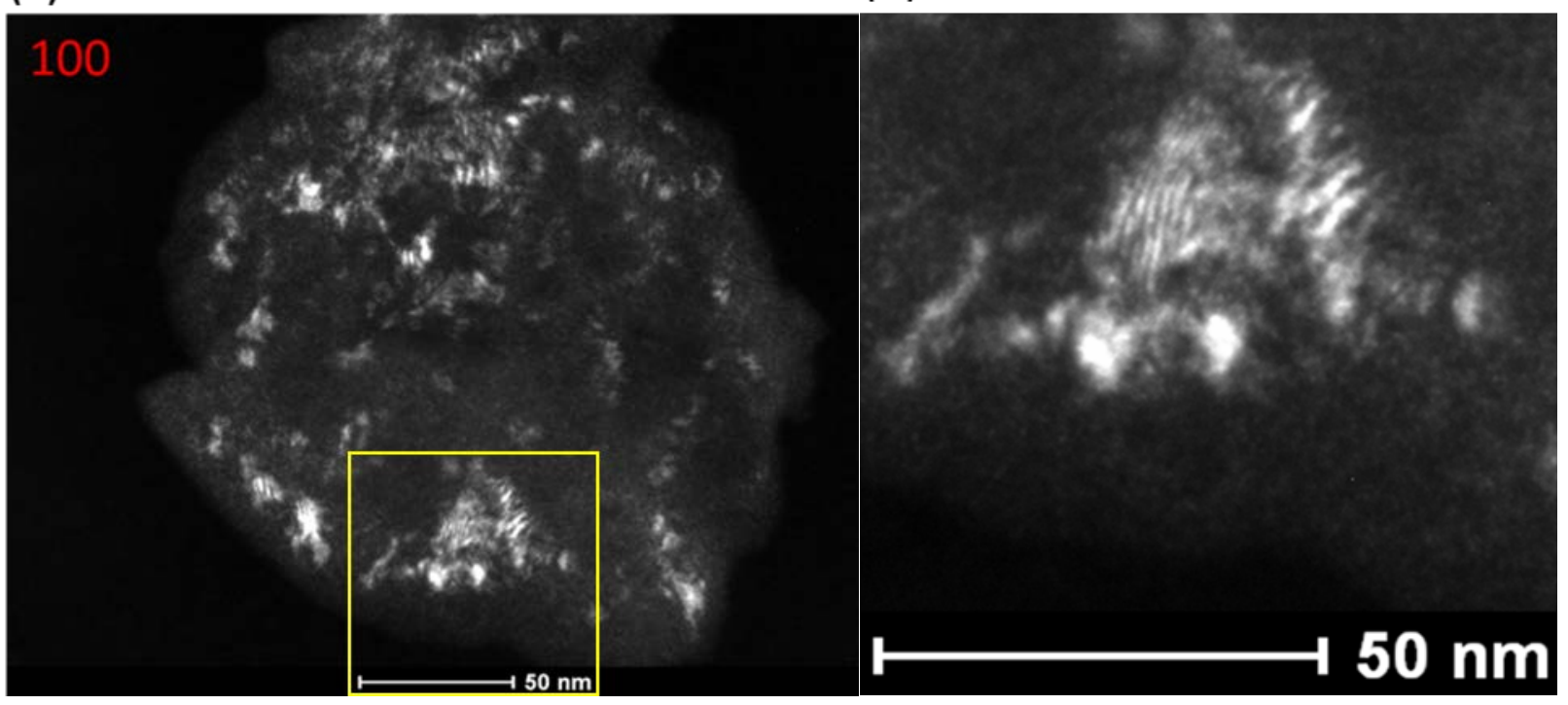

(e)
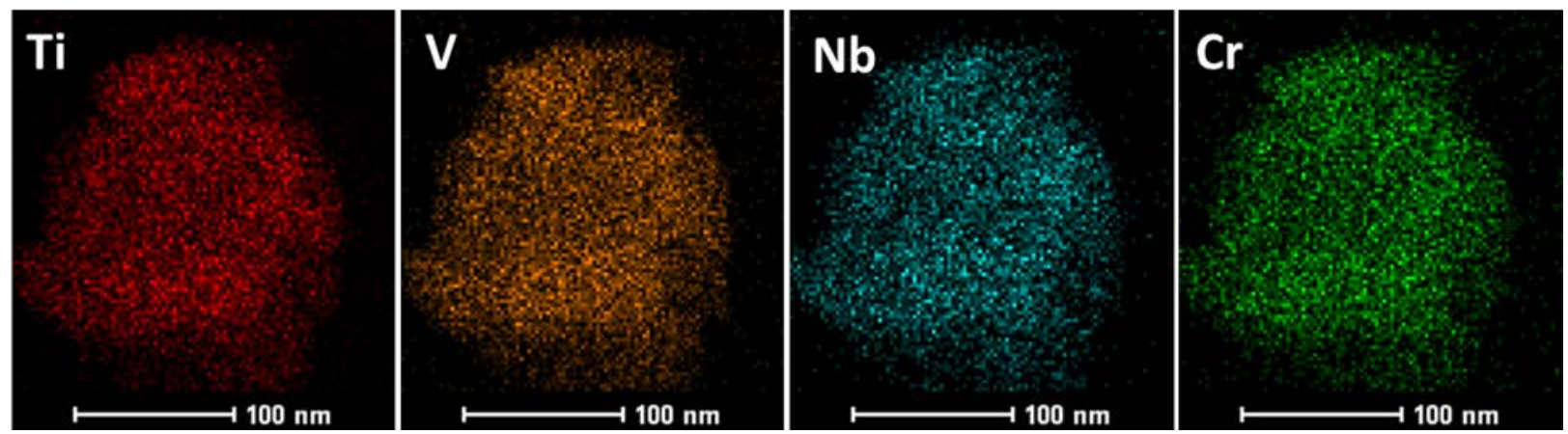

Figure 6: TEM images of (TiVNb) ${ }_{85} \mathrm{Cr}_{15}$ alloy hydrogenated up to $0.5 \mathrm{H} / \mathrm{M}$ (a) Bright field image (b) SAEDP showing the BCC ring reflections (c) Dark field image (d) Region highlighted in yellow (e) EDS mapping.

Table 3: Chemical composition in at.\% of the analyzed particle from sample (2) via TEM-EDS.

\begin{tabular}{|c|c|c|c|c|}
\hline Element & $\mathbf{T i}$ & $\mathbf{V}$ & $\mathbf{N b}$ & $\mathbf{C r}$ \\
\hline at. \% & 29.8 & 28.6 & 26.8 & 14.7 \\
\hline
\end{tabular}

In summary, we showed clear evidence by structural characterization and absorption/desorption analyses that the (TiVNb) ${ }_{85} \mathrm{Cr}_{15}$ alloy presented multi-step absorption/desorption reactions. We demonstrated that the formation of the intermediate hydride 
results from a miscibility gap in the BCC phase. Therefore, we propose that the absorption process for these alloys is completely described as follows: initially, the BCC alloys absorb hydrogen by forming a random solid solution until the solubility limit of this phase is attained and a second BCC phase with higher H content (intermediate hydride) starts to coexist. When all the BCC solid solution phase is converted to the intermediate hydride, the $\mathrm{H}$ concentration of the intermediate hydride increases until its solubility limit is attained. At this point, the intermediate hydride and the dihydride phases start to coexist. When all the intermediate hydride is converted to the dihydride, the $\mathrm{H}$ content on the dihydride increases until its solubility limit is attained. During desorption, the opposite reactions steps takes place.

\section{Conclusions}

We investigated the reactions of absorption and desorption of the (TiVNb) ${ }_{85} \mathrm{Cr}_{15}$ alloy. Several evidence of multi-step processes of absorption/desorption were observed. We confirmed a miscibility gap in the BCC alloys, which results in the formation of an intermediate BCC hydride. Moreover, the average and local structures of the alloys partially hydrogenated with $0.5 \mathrm{H} / \mathrm{M}$ and 1.6 H/M and the alloy fully hydrogenated with $2 \mathrm{H} / \mathrm{M}$ seemed to be reasonably described by models with random atomic distribution in the metal crystallographic sites for both BCC and FCC structures, suggesting that no significant local ordering is introduced by $\mathrm{H}$ absorption.

\section{Acknowledgments}

This work was financed in part by the Serrapilheira Institute (grant number Serra-170917362), in part by the Conselho Nacional de Desenvolvimento Científico e Tecnológico - CNPq (Project number: 142446/2019-0), in part by the CAPES-COFECUB cooperation program process number 88887.387430/2019-00, project number 88887.191910/2018-00 and in part by the grant 2020/07707-6, São Paulo Research Foundation (FAPESP).This study was financed in part by the Coordenação de Aperfeiçoamento de Pessoal de Nível Superior - Brasil (CAPES) - Finance Code 001.

\section{Data availability statement}

The data used in this manuscript is available for reproduction upon request. 


\section{References}

[1] N.L. Panwar, S.C. Kaushik, S. Kothari, Role of renewable energy sources in environmental protection: A review, Renew. Sustain. Energy Rev. 15 (2011) 1513-1524. doi:10.1016/j.rser.2010.11.037.

[2] K.T. Møller, T.R. Jensen, E. Akiba, H. wen Li, Hydrogen - A sustainable energy carrier, Prog. Nat. Sci. Mater. Int. 27 (2017) 34-40. doi:10.1016/j.pnsc.2016.12.014.

[3] A. Züttel, A. Remhof, A. Borgschulte, O. Friedrichs, Hydrogen: The future energy carrier, Philos. Trans. R. Soc. A Math. Phys. Eng. Sci. 368 (2010) 3329-3342.

doi:10.1098/rsta.2010.0113.

[4] R. Moradi, K.M. Groth, Hydrogen storage and delivery: Review of the state of the art technologies and risk and reliability analysis, Int. J. Hydrogen Energy. 44 (2019) 1225412269. doi:10.1016/j.ijhydene.2019.03.041.

[5] M.W. Davids, M. Lototskyy, M. Malinowski, D. van Schalkwyk, A. Parsons, S. Pasupathi, D. Swanepoel, T. van Niekerk, Metal hydride hydrogen storage tank for light fuel cell vehicle, Int. J. Hydrogen Energy. 44 (2019) 29263-29272. doi:10.1016/j.ijhydene.2019.01.227.

[6] P. Wyckaert, S. Nadeau, H. Bouzid, Analysis of Risks of Pressure Vessels, Kongress Der Gesellschaft Für Arbeitswiss. FHNW Brugg-Windisch, Schweiz. (2017). https://www.researchgate.net/publication/313985693\%0Ahttp://www.iaeng.org/publicatio n/WCE2010/WCE2010_pp1120-1123.pdf.

[7] B. Sakintuna, F. Lamari-Darkrim, M. Hirscher, Metal hydride materials for solid hydrogen storage: A review, Int. J. Hydrogen Energy. 32 (2007) 1121-1140. doi:10.1016/j.ijhydene.2006.11.022.

[8] N.A.A. Rusman, M. Dahari, A review on the current progress of metal hydrides material for solid-state hydrogen storage applications, Int. J. Hydrogen Energy. 41 (2016) 1210812126. doi:10.1016/j.ijhydene.2016.05.244.

[9] K. Young, Metal Hydrides $\aleph^{2}$, in: Ref. Modul. Chem. Mol. Sci. Chem. Eng., Elsevier, 2018. doi:https://doi.org/10.1016/B978-0-12-409547-2.05894-7. 
[10] M. Dornheim, Thermodynamics of Metal Hydrides: Tailoring Reaction Enthalpies of Hydrogen Storage Materials, Thermodyn. - Interact. Stud. - Solids, Liq. Gases. (2011). doi:10.5772/21662.

[11] D.B. Miracle, O.N. Senkov, A critical review of high entropy alloys and related concepts, Acta Mater. 122 (2017) 448-511. doi:10.1016/j.actamat.2016.08.081.

[12] J. Hu, H. Shen, M. Jiang, H. Gong, H. Xiao, Z. Liu, G. Sun, X. Zu, A DFT study of hydrogen storage in high-entropy alloy TiZrHfScMo, Nanomaterials. 9 (2019) 1-12. doi:10.3390/nano9030461.

[13] I. Kunce, M. Polański, T. Czujko, Microstructures and hydrogen storage properties of LaNi-Fe-V-Mn alloys, Int. J. Hydrogen Energy. 42 (2017) 27154-27164. doi:10.1016/j.ijhydene.2017.09.039.

[14] D. Karlsson, G. Ek, J. Cedervall, C. Zlotea, K.T. Møller, T.C. Hansen, J. Bednarčík, M. Paskevicius, M.H. Sørby, T.R. Jensen, U. Jansson, M. Sahlberg, Structure and Hydrogenation Properties of a HfNbTiVZr High-Entropy Alloy, Inorg. Chem. 57 (2018) 2103-2110. doi:10.1021/acs.inorgchem.7b03004.

[15] G. Zepon, D.R. Leiva, R.B. Strozi, A. Bedoch, S.J.A. Figueroa, T.T. Ishikawa, W.J. Botta, Hydrogen-induced phase transition of MgZrTiFe0.5Co0.5Ni0.5 high entropy alloy, Int. J. Hydrogen Energy. 43 (2018) 1702-1708. doi:10.1016/j.ijhydene.2017.11.106.

[16] I. Kunce, M. Polanski, J. Bystrzycki, Microstructure and hydrogen storage properties of a TiZrNbMoV high entropy alloy synthesized using Laser Engineered Net Shaping (LENS), Int. J. Hydrogen Energy. 39 (2014) 9904-9910. doi:10.1016/j.ijhydene.2014.02.067.

[17] I. Kunce, M. Polanski, J. Bystrzycki, Structure and hydrogen storage properties of a high entropy ZrTiVCrFeNi alloy synthesized using Laser Engineered Net Shaping (LENS), Int. J. Hydrogen Energy. 38 (2013) 12180-12189. doi:10.1016/j.ijhydene.2013.05.071.

[18] Y.F. Kao, S.K. Chen, J.H. Sheu, J.T. Lin, W.E. Lin, J.W. Yeh, S.J. Lin, T.H. Liou, C.W. Wang, Hydrogen storage properties of multi-principal-component CoFeMnTi xVyZrz alloys, Int. J. Hydrogen Energy. 35 (2010) 9046-9059. doi:10.1016/j.ijhydene.2010.06.012. 
[19] M.M. Nygård, G. Ek, D. Karlsson, M. Sahlberg, M.H. Sørby, B.C. Hauback, Hydrogen storage in high-entropy alloys with varying degree of local lattice strain, Int. J. Hydrogen Energy. 44 (2019) 29140-29149. doi:10.1016/j.ijhydene.2019.03.223.

[20] C. Zhang, Y. Wu, L. You, X. Cao, Z. Lu, X. Song, Investigation on the activation mechanism of hydrogen absorption in TiZrNbTa high entropy alloy, J. Alloys Compd. 781 (2019) 613-620. doi:10.1016/j.jallcom.2018.12.120.

[21] P. Edalati, R. Floriano, A. Mohammadi, Y. Li, G. Zepon, H.W. Li, K. Edalati, Reversible room temperature hydrogen storage in high-entropy alloy TiZrCrMnFeNi, Scr. Mater. 178 (2020) 387-390. doi:10.1016/j.scriptamat.2019.12.009.

[22] H. Shen, J. Hu, P. Li, G. Huang, J. Zhang, J. Zhang, Y. Mao, H. Xiao, X. Zhou, X. Zu, X. Long, S. Peng, Compositional dependence of hydrogenation performance of Ti-Zr-HfMo-Nb high-entropy alloys for hydrogen/tritium storage, J. Mater. Sci. Technol. (2020). doi:10.1016/j.jmst.2019.08.060.

[23] B.H. Silva, C. Zlotea, Y. Champion, W.J. Botta, G. Zepon, Design of TiVNb-(Cr, Ni or Co) multicomponent alloys with the same valence electron concentration for hydrogen storage, J. Alloys Compd. 865 (2021) 158767. doi:10.1016/j.jallcom.2021.158767.

[24] M.M. Nygård, G. Ek, D. Karlsson, M.H. Sørby, M. Sahlberg, B.C. Hauback, Counting electrons - A new approach to tailor the hydrogen sorption properties of high-entropy alloys, Acta Mater. 175 (2019) 121-129. doi:10.1016/j.actamat.2019.06.002.

[25] R.B. Strozi, D.R. Leiva, G. Zepon, W.J. Botta, J. Huot, Effects of the chromium content in (Tivnb)100-xcrx body-centered cubic high entropy alloys designed for hydrogen storage applications, Energies. 14 (2021). doi:10.3390/en14113068.

[26] G. Zepon, B.H. Silva, C. Zlotea, W.J. Botta, Y. Champion, Thermodynamic modelling of hydrogen-multicomponent alloy systems: Calculating pressure-composition-temperature diagrams, Acta Mater. 215 (2021) 117070. doi:10.1016/j.actamat.2021.117070.

[27] M. Sahlberg, D. Karlsson, C. Zlotea, U. Jansson, Superior hydrogen storage in high entropy alloys, Sci. Rep. 6 (2016) 1-6. doi:10.1038/srep36770.

[28] M.M. Nygård, Ø.S. Fjellvåg, M.H. Sørby, K. Sakaki, K. Ikeda, J. Armstrong, P. 
Vajeeston, W.A. Sławiński, H. Kim, A. Machida, Y. Nakamura, B.C. Hauback, The average and local structure of TiVCrNbDx $(x=0,2.2,8)$ from total scattering and neutron spectroscopy, Acta Mater. 205 (2021). doi:10.1016/j.actamat.2020.116496.

[29] C. Zlotea, M.A. Sow, G. Ek, J.P. Couzinié, L. Perrière, I. Guillot, J. Bourgon, K.T. Møller, T.R. Jensen, E. Akiba, M. Sahlberg, Hydrogen sorption in TiZrNbHfTa high entropy alloy, J. Alloys Compd. 775 (2019) 667-674. doi:10.1016/j.jallcom.2018.10.108.

[30] K. Sakaki, H. Kim, K. Asano, Y. Nakamura, Hydrogen storage properties of Nb-based solid solution alloys with a BCC structure, J. Alloys Compd. 820 (2020) 153399. doi:10.1016/j.jallcom.2019.153399.

[31] J. Montero, G. Ek, L. Laversenne, V. Nassif, G. Zepon, M. Sahlberg, C. Zlotea, Hydrogen storage properties of the refractory $\mathrm{Ti}-\mathrm{V}-\mathrm{Zr}-\mathrm{Nb}-\mathrm{Ta}$ multi-principal element alloy, $\mathrm{J}$. Alloys Compd. 835 (2020) 155376. doi:10.1016/j.jallcom.2020.155376.

[32] G.B.M. Vaughan, R. Baker, R. Barret, J. Bonnefoy, T. Buslaps, S. Checchia, D. Duran, F. Fihman, P. Got, J. Kieffer, S.A.J. Kimber, K. Martel, C. Morawe, D. Mottin, E. Papillon, S. Petitdemange, A. Vamvakeros, J.P. Vieux, M. Di Michiel, ID15A at the ESRF-a beamline for high speed operando X-ray diffraction, diffraction tomography and total scattering, J. Synchrotron Radiat. 27 (2020) 515-528. doi:10.1107/S1600577519016813.

[33] J. Kieffer, S. Petitdemange, T. Vincent, Real-time diffraction computed tomography data reduction, J. Synchrotron Radiat. 25 (2018) 612-617. doi:10.1107/S1600577518000607.

[34] G. Ashiotis, A. Deschildre, Z. Nawaz, J.P. Wright, D. Karkoulis, F.E. Picca, J. Kieffer, The fast azimuthal integration Python library: PyFAI, J. Appl. Crystallogr. 48 (2015) 510519. doi:10.1107/S1600576715004306.

[35] P. Juhás, C. Farrow, X. Yang, K. Knox, S. L. Billinge, Complex modeling: a strategy and software program for combining multiple information sources to solve ill posed structure and nanostructure inverse problems, Acta Crystallogr. Sect. A. 71 (2015) 562568. doi:10.1107/S2053273315014473.

[36] B.H. Toby, R.B. Von Dreele, GSAS-II: the genesis of a modern open-source all purpose crystallography software package, J. Appl. Crystallogr. 46 (2013) 544-549. 
doi:10.1107/S0021889813003531.

[37] C.L. Farrow, P. Juhas, J.W. Liu, D. Bryndin, E.S. Boin, J. Bloch, T. Proffen, S.J.L. Billinge, PDFfit2 and PDFgui: Computer programs for studying nanostructure in crystals, J. Phys. Condens. Matter. 19 (2007). doi:10.1088/0953-8984/19/33/335219.

[38] T. Tamura, A. Kamegawa, H. Takamura, M. Okada, Protium absorption properties of TiCr-V alloys in low hydrogen pressure regions, Mater. Trans. 42 (2001) 1862-1865.

[39] T. Tamura, M. Hatakeyama, T. Ebinuma, A. Kamegawa, H. Takamura, M. Okada, Protium absorption properties of Ti-Cr-V-Mn alloys in low pressure regions, Mater. Trans. 43 (2002) 1120-1123. doi:10.2320/matertrans.43.1120.

[40] G. Ek, M.M. Nygård, A.F. Pavan, J. Montero, P.F. Henry, M.H. Sørby, M. Witman, V. Stavila, C. Zlotea, B.C. Hauback, M. Sahlberg, Elucidating the Effects of the Composition on Hydrogen Sorption in TiVZrNbHf-Based High-Entropy Alloys, Inorg. Chem. 60 (2021) 1124-1132. doi:10.1021/acs.inorgchem.0c03270.

[41] M.M. Nygård, W.A. Sławiński, G. Ek, M.H. Sørby, M. Sahlberg, D.A. Keen, B.C. Hauback, Local order in high-entropy alloys and associated deuterides - a total scattering and Reverse Monte Carlo study, Acta Mater. 199 (2020) 504-513. doi:10.1016/j.actamat.2020.08.045. 